\title{
What Future Healthcare Professionals Need to Know About Pharmacovigilance: Introduction of the WHO PV Core Curriculum for University Teaching with Focus on Clinical Aspects
}

\author{
Rike van Eekeren ${ }^{1,2}$ (1) $\cdot$ Leàn Rolfes ${ }^{1,2} \cdot$ Andries S. Koster $^{3}$ (i) Lara Magro $^{4}$ • \\ Gurumurthy Parthasarathi $^{5} \cdot$ Hussain Al Ramimmy $^{6} \cdot$ Tim Schutte $^{7,8}$ (I) $\cdot$ \\ Daisuke Tanaka $^{9}$ Eugène van Puijenbroek ${ }^{1,2} \cdot$ Linda Härmark $^{1}$
}

Published online: 13 June 2018

(C) The Author(s) 2018

\begin{abstract}
Adverse drug reactions (ADRs) can cause serious health problems, as shown in studies about drug-related hospitalizations. To build knowledge of and raise awareness about ADRs among healthcare professionals, more education in the field of ADRs and pharmacovigilance (PV) is needed. No standard exists for teaching PV at universities for medical, pharmacy, dentistry and nursing students, so a core curriculum needs to be developed to teach important aspects of PV to students. In September 2016, a stakeholders' meeting was initiated on behalf of the World Health Organization (WHO) and organized by the Netherlands
\end{abstract}

Rike van Eekeren

r.van.eekeren-buiten@rug.nl

1 Netherlands Pharmacovigilance Centre Lareb, WHO Collaborating Centre For Pharmacovigilance in Education and Patient Reporting, Goudsbloemvallei 7, $5237 \mathrm{MH}$ 's-Hertogenbosch, The Netherlands

2 University of Groningen, Groningen Research Institute of Pharmacy, PharmacoTherapy, -Epidemiology and -Economics, PO Box 196, Groningen 9700 AD, The Netherlands

3 Department of Pharmaceutical Sciences, University of Utrecht, Utrecht, The Netherlands

4 Department of Diagnostics and Public Health, Section of Pharmacology, University of Verona, Verona, Italy

5 JSS College of Pharmacy, JSS University, Mysore, India

6 Department of Pharmacovigilance and Drug Information, Directorate General of Pharmaceutical Affairs and Drug Control, Ministry of Health, Muscat, Sultanate of Oman

7 Department of Internal Medicine, VU University Medical Center, Amsterdam, The Netherlands

8 RECIPE (Research and Expertise Center in Pharmacotherapy Education), Amsterdam, The Netherlands

9 WHO, Geneva, Switzerland
Pharmacovigilance Centre Lareb. This meeting addressed and agreed on the PV competencies students need to develop and what key aspects of the subject should be taught. Five key aspects were identified: understanding the importance of $\mathrm{PV}$ in the context of pharmacotherapy, and preventing, recognizing, managing and reporting ADRs. Since time and resources for PV education are limited, elements of the WHO $\mathrm{PV}$ core curriculum for university teaching were designed to be integrated into existing courses but can be used as a standalone programme. The basis of and outline for the WHO PV core curriculum for university teaching are addressed in this paper. It is expected that PV competencies for students are vital for their contribution to safe use of medicines in the future. In addition, this article aims to stimulate discussion on this subject and promote collaboration between universities, national PV centres and other stakeholders to integrate key aspects of PV in their educational programmes.

\section{Key Points}

The World Health Organization (WHO)

pharmacovigilance (PV) core curriculum for university teaching focusses on clinical aspects and can be integrated into existing courses such as pharmacology and pharmacotherapy or used as a stand-alone course.

Key aspects of the WHO PV core curriculum for university teaching are understanding the importance of pharmacovigilance and preventing, recognizing, managing, and—finally—reporting adverse drug reactions. 


\section{Introduction}

Medicines help us treat many diseases, but adverse drug reactions (ADRs) cause serious health problems. Studies indicate that ADRs account for approximately 5\% of all acute hospitalizations [1-3]. About half of these hospitalizations could have been prevented by more effective drug therapy monitoring, timely recognition of the symptoms, and knowledge about certain risk factors for occurrence of these ADRs [1, 2]. From the patients' perspective, all ADRs are important. All ADRs can pose a problem and may negatively influence quality of life and drug adherence, irrespective of seriousness and whether they arise from medication errors [4]. Sufficient knowledge of and skills around the safety of medicines and safe use of drugs in daily practice are important for all healthcare professionals (HCPs) who are directly involved in pharmacotherapy, such as doctors, pharmacists, dentists and nurses, to reduce drug-induced patient harm [5].

Competence in handling ADRs in clinical practice is important, not only for patient safety in individual patient care but also for drug safety monitoring at a population level. The science and activities relating to the detection, assessment, understanding and prevention of adverse effects or any other drug-related problem is called pharmacovigilance (PV) [6]. Although medical and pharmacy students may recognize the importance of ADR reporting and express the intention to report ADRs, they are insufficiently prepared to handle ADRs and have inadequate PV competencies [7-11]. This hampers optimal patient care and the safe use of drugs now and in the future [7]. For future HCPs to be competent in handling ADRs in clinical practice and reporting them, more education is needed [12].

HCPs often consider ADR reporting to be an additional activity rather than routine practice [13]. Beyond improvement of PV education at the university level, continuous educational interventions for practicing HCPs have proven to be effective in PV competencies [14]. Besides education, inter-professional collaboration improves the culture in healthcare in terms of recognizing ADRs and the awareness of ADR reporting [15].

To acknowledge the importance of safety issues in drug treatment, PV education should be introduced at an early stage, along with patient care as part of the Hippocratic Oath "first, do no harm". Since students are accustomed to acquiring new knowledge and skills, it can be expected that PV education of students at university level will improve knowledge about safety of medicines and skills for a safer use of medicines at an early stage of their career $[12,16]$.

\section{Development of a Practical Pharmacovigilance (PV) Curriculum for University Teaching}

To teach important aspects of PV to undergraduate students, a core curriculum that describes desired competencies and learning outcomes and provides practical materials needs to be developed. Although patient safety, safe prescribing and PV are increasingly recognized as important topics in university educational frameworks worldwide, in many countries this education depends on individual professors or active PV centres [5, 12, 17-19].

Although there are initiatives to support education in the field of patient safety and PV in general, there is no standard programme about PV for university teaching. In 2011, the World Health Organization (WHO) established the WHO Patient Safety curriculum for undergraduate students. Although this curriculum contains medication errors and related adverse events, some aspects related to PV are still missing [20]. The WHO-International Society of Pharmacovigilance (ISoP) curriculum for PV teaching, designed for people interested in PV in any setting, consists of a comprehensive list of topics that cover almost all aspects of PV. Relevant topics for university teaching can be selected by users, but practical information about implementation of relevant sections of this curriculum and ready-to-use-teaching materials and an undergraduate course description should be developed [21, 22]. The European programme in Pharmacovigilance and Pharmacoepidemiology (EU2P) also offers education and training in pharmacovigilance for individuals with a special interest in PV [23]. For the broad audience of medical, pharmacy and nursing students in general, a manageable curriculum or programme is needed.

In September 2016, a stakeholder's meeting was initiated on behalf of the WHO, under its Programme of International Drug Monitoring, and organized by The Netherlands Pharmacovigilance Centre Lareb WHO Collaborating Centre for Pharmacovigilance in Education and Patient Reporting. Meeting participants had backgrounds in medical or pharmacy teaching, PV and governmental positions and came from various continents (for details see the co-author section). This meeting addressed and agreed on the competencies in the field of PV students at university level need to develop and the key aspects that should be taught.

In this article, we outline the key aspects and competencies that form a PV core curriculum for university education. The key aspects of PV can be integrated in existing courses for medical, pharmacy, dentistry and nursing education. The curriculum can also be used as a stand-alone programme. To our knowledge, the WHO PV 
Table 1 Summary of the key aspects and content of the World Health Organization pharmacovigilance core curriculum for university teaching

\begin{tabular}{|c|c|c|c|c|}
\hline Key aspect & Knowledge & Skills & Attitude & $\begin{array}{l}\text { Examples of } \\
\text { teaching methods }\end{array}$ \\
\hline $\begin{array}{l}\text { Understanding the } \\
\text { importance of PV }\end{array}$ & $\begin{array}{l}\text { Drug-induced harm and } \\
\text { hospital admissions } \\
\text { Historical examples }\end{array}$ & $\begin{array}{l}\text { Recognizing ADRs and their } \\
\text { impact on individual patients }\end{array}$ & $\begin{array}{l}\text { Open mindedness of } \\
\text { adverse outcomes of } \\
\text { drug use in } \\
\text { pharmacotherapy }\end{array}$ & $\begin{array}{l}\text { Story telling } \\
\text { Patient interview }\end{array}$ \\
\hline Preventing ADRs & $\begin{array}{l}\text { General risk factors } \\
\text { Individual risk factors } \\
\text { Treatment guidelines and } \\
\text { safety information }\end{array}$ & Choose right drug treatment & $\begin{array}{l}\text { Safe prescribing/ } \\
\text { dispensing }\end{array}$ & $\begin{array}{l}\text { Problem solving } \\
\text { Simulation, role play } \\
\text { ADR monograph } \\
\text { ADR report }\end{array}$ \\
\hline Recognizing ADRs & $\begin{array}{l}\text { ADR classification } \\
\text { Risk factors } \\
\text { Confounding factors } \\
\text { Epidemiology }\end{array}$ & $\begin{array}{l}\text { Clinical reasoning } \\
\text { Causality reasoning }\end{array}$ & $\begin{array}{l}\text { Awareness of } \\
\text { predictable and } \\
\text { unexpected ADRs }\end{array}$ & $\begin{array}{l}\text { assessment } \\
\text { Prescribing safety } \\
\text { assessment } \\
\text { Internship }\end{array}$ \\
\hline Managing ADRs & $\begin{array}{l}\text { ADR classification } \\
\text { Seriousness } \\
\text { Severity }\end{array}$ & $\begin{array}{l}\text { Choose right actions; patient } \\
\text { and HCP communication; } \\
\text { recording of ADR data }\end{array}$ & $\begin{array}{l}\text { Optimize risk-benefit } \\
\text { balance in an } \\
\text { individual patient }\end{array}$ & \\
\hline Reporting ADRs & $\begin{array}{l}\text { Limitations of premarketing } \\
\text { phase } \\
\text { Relevance of ADR reporting } \\
\text { Documentation of ADRs }\end{array}$ & $\begin{array}{l}\text { Recognizing ADRs in practice } \\
\text { Complete reporting form }\end{array}$ & $\begin{array}{l}\text { Responsibility for } \\
\text { sharing (reporting) of } \\
\text { ADRs }\end{array}$ & $\begin{array}{l}\text { ADR reporting } \\
\text { assignment }\end{array}$ \\
\hline
\end{tabular}

The WHO PV core curriculum for university teaching has five key aspects, which are the desired learning outcomes for future HCPs. Based on Bloom's taxonomy, learning objectives can be determined in a structured way. In its basic form, there are three categories of learning: knowledge, skills and attitudes [35]. Knowledge, skills and attitudes for each learning outcome (key aspect) in the WHO PV core curriculum for university teaching have been defined. Examples of teaching methods are added to the table for a complete overview of the WHO PV core curriculum for university teaching

$A D R$ adverse drug reaction, $H C P$ healthcare professional, $P V$ pharmacovigilance, $W H O$ World Health Organization

core curriculum for university teaching is the first to be described in the literature.

\section{Key Aspects of PV Education}

PV entails various aspects of science and activities related to the safety and safe use of medicines throughout the entire lifecycle of a drug, from clinical research to postauthorisation phase. It is strongly associated with both regulatory aspects and clinical pharmacology. Since most students will work in clinical practice and provide patientcare services after graduation, our aim is to focus on the clinical aspects of PV and the use of authorised drugs as desired learning outcomes. The proposed key aspects, formulated as learning outcomes of undergraduate PV education, are as follows:

1. understanding the importance of PV in the context of pharmacotherapy

2. preventing ADRs when possible

3. recognizing ADRs when they occur

4. managing ADRs

5. reporting ADRs.
The PV key aspects are summarized in Table 1 and explained in more detail in the following sections, see also Fig. 1.

\subsection{Understanding the Importance of PV in the Context of Pharmacotherapy}

Awareness of the impact of ADRs on individual patients is important for undergraduate students to understand patients' perspectives on safety issues. The stories of patients who have experienced ADRs will elucidate the impact of ADRs to students. Both serious and non-serious ADRs may negatively influence patients' quality of life and treatment satisfaction and hamper drug compliance [24].

Students also need knowledge of the extent of druginduced harm at a population level, which can be visualized using drug-related hospital admissions [1,2] and with historical examples of drug-induced disasters such as limb deformities following maternal use of thalidomide [25]. These examples gave rise to the present-day regulatory framework and the way in which the safety monitoring of drugs is organized. 


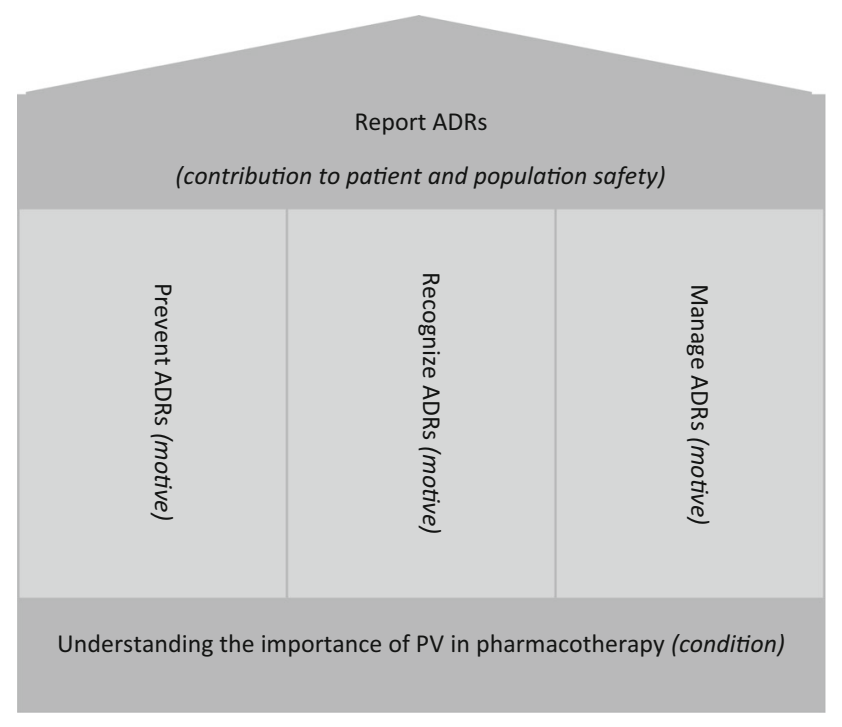

Fig. 1 House of PV in clinical practice. The foundation of PV in clinical practice is understanding the importance of $\mathrm{PV}$ in the context of pharmacotherapy and creating awareness of occurrence of safety issues during pharmacotherapy. Understanding the importance of PV, as well as the awareness of ADRs, is conditional for recognition, management and prevention of ADRs. These are the three main walls of preventing drug-induced harm in patients. Experienced druginduced harm is a motive for reporting ADRs, shown here as the roof of the house, as an individual's contribution to increasing the knowledge of ADRs and detecting new signals of potential risks. Knowledge of ADRs provides more insight into the occurrence of ADRs in patients, which can be used directly in clinical practice. $A D R$ adverse drug reaction, $P V$ pharmacovigilance

\subsection{Preventing Adverse Drug Reactions (ADRs)}

Safe and rational prescribing and dispensing of drugs entails therapeutic reasoning and decision making, such as choosing the right drug for each individual patient. The occurrence of an ADR to previous treatment, as well as the individual patient's risk factors should influence this choice. Students need to learn how to consider all circumstances that influence the occurrence of ADRs in a patient. This implies knowledge of general risk factors, such as the increased incidence of ADRs in the elderly, as well as individual risk factors related to a certain drug or to a person's medical condition, such as comorbidity and genetic factors. Drug-drug interactions can be expected when patients use concomitant medication, especially in polypharmacy [26], or when patients use herbal or other traditional medicines [27]. Food-drug interactions may influence drug absorption or drug metabolism; for example, grapefruit juice inhibits drugs metabolized by cytochrome P450 (CYP)-3A4 [28]. Information on these risk factors is generally available in drug labelling, treatment guidelines and medical literature, which students must learn to use and interpret.

\subsection{Recognizing ADRs}

It is important that students learn how to recognize symptoms of ADRs in patients. Identifying ADRs can be difficult, because sometimes they are hard to distinguish from underlying disease or comorbidity. This requires knowledge of clinical pharmacological principles of ADRs, such as types of ADRs, dose-relatedness, pharmacological actions, hypersensitivity reactions, time relationship and risk factors $[29,30]$. Training in clinical reasoning with a focus on causality reasoning is important to distinguish a suspected ADR from other medical conditions or background incidence.

Observations of ADRs and designing individual treatment plans for managing ADRs will strongly contribute to the development of awareness of the impact of ADRs in patients and on the importance of $\mathrm{PV}$ at a population level.

\subsection{Managing ADRs}

Patients who experience an ADR need special and individual attention. The impact of ADRs ranges from absent or mild influence on quality of life to life-threatening situations, such as anaphylaxis or intracranial haemorrhages. Furthermore, ADRs may negatively influence a patient's compliance with therapy. Therefore, depending on the indication, seriousness, perceived severity and prognosis, patients and HCPs must design an individual treatment plan. Actions for treatment include drug discontinuation, dose adjustment or additional treatment of the symptoms. Sometimes, alternative treatment for the initial disease should be chosen. After experiencing a severe ADR, patients might fear drug treatment in general [31]. Students need the skills and knowledge to classify an ADR and the competence to respond when they come across serious or severe ADRs, which can be difficult.

Communication skills are also needed to better explain safety data to colleagues and patients and encourage and understand feedback from those involved in PV [32].

Students should furthermore develop the ability to explain ADRs to patients and their families, advising about future drug use and the chances of the ADR recurring [33].

Finally, relevant elements of the ADR should be recorded properly into the patient's healthcare record.

\subsection{Reporting ADRs}

Beyond the awareness of ADRs in individual patients, PV also focusses on the improvement of public health regarding the safety and safe use of medicines. Students need to understand that information on ADRs from the premarketing phase is limited. HCPs have a responsibility to share their clinical practice experience in the real world 
Fig. 2 Example of curriculum levels of competence in PV education. The pyramid shows increasing complexity of key $\mathrm{PV}$ aspects during university education. Depending on the local situation and structure of the educational programme, a Bachelor/Master division may be absent. Apart from the structure, increasingly complex learning outcomes can be offered throughout the programme. $A D R$ adverse drug reaction, $P V$

pharmacovigilance. Adapted from Koster et al. [36]

\section{MASTER: The student .....}

..... is able to anticipate on potential adverse drug reactions when prescribing or designing a pharmacotherapeutic treatment plan for an individual patient;

..... is able to recognize and interpret (expected and unexpected) adverse drug reactions, occurring in real-life patients;

..... is able to design effective treatment interventions for patients, suffering from adverse drug reactions;

..... is able to report adverse drug reactions to the locally recognized authorities.

\section{BACHELOR: The student.....}

..... is able to identify adverse drug reactions in authentic descriptions or examples of (relatively simple) patient cases;

..... is able to explain the mechanism of relatively simple adverse drug reactions in terms of pharmacological, toxicological principles and/or individual risk factors;

..... is able to suggest pharmacotherapeutic interventions for relatively simple cases of adverse drug reactions.

YEAR 1: The student .....

..... knows the concept 'pharmacovigilance' and is able to describe the importance of preventing, recognizing, managing and reporting adverse drug reactions;

..... is able to give historical and current examples of drug-induced harm. with regulatory authorities. Spontaneous reporting systems continue to be an effective method of signal detection [34]. ADR reports from HCPs and patients often trigger the detection of potential new medicines safety signals. They improve general information about ADRs. Reporting an ADR to PV centres or other relevant organisations is a skill that can be developed easily during clinical internships [4, 32].

\section{Integration of PV Key Aspects in Existing Educational Programmes}

\subsection{PV Competencies for Future Healthcare Professionals}

Competency-based educational models are becoming more dominant than the traditional content-driven and teachercentred learning methods in university teaching [36, 37]. A competency can be described as an individual's ability to make deliberate choices for handling situations and tasks in specific contexts of professional practice [36]. In the context of pharmacotherapy, competencies in PV are the timely recognition, prevention and management of ADRs.

To acquire competencies, different learning outcomes with skills, knowledge and attitudes can be defined [35]. Competencies in PV were first described by Edwards et al.
[32] in 2006. In the broad context of professional PV, healthcare professionals in clinical practice must ensure the safe use of drugs and contribute to the reporting of ADRs.

We summarized learning outcomes regarding these competencies as key PV aspects (Table 1). Students develop different levels of competence throughout their educational career, which require adjusted and aligned learning activities. Figure 2 illustrates how the related key PV aspects can be divided into levels of competence throughout university education. By offering key PV aspects with increasing complexity at different stages of education, students will acknowledge the importance of the subject and will be challenged and motivated to learn.

\subsection{Practical Aspects}

The importance of PV can be taught from the first year of education, since limited specific knowledge is required. The clinical aspects of PV can be considered logical extensions of general subjects such as pharmacology and toxicology. The actual recognition, management and prevention of ADRs therefore requires broad knowledge and skills from pharmacology, pharmacokinetics, pathophysiology, pharmacotherapy, drug development, pharmaceutical regulations, epidemiology and general science. This implies the integration of key PV aspects becomes feasible later on in the Bachelor or Master phases, depending on the 
Table 2 Examples of methods in pharmacovigilance education at university level, ordered in type of students, educational phase and kinds of learning activities

\begin{tabular}{|c|c|c|c|c|}
\hline Method & Students & Phase & Learning activities & Countries \\
\hline ADR reporting & Pharmacy and medical & Master/internship & $\begin{array}{l}\text { Collecting ADRs, questioning } \\
\text { patients, Reporting ADRs }\end{array}$ & $\begin{array}{l}\text { Turkey [16] } \\
\text { USA [53] } \\
\text { USA [54] } \\
\text { Denmark [55] } \\
\text { Iran [56] } \\
\text { India [57] }\end{array}$ \\
\hline PV course & Pharmacy & Bachelor 3rd year & $\begin{array}{l}\text { Lectures, causality assessment, } \\
\text { design reporting form, group } \\
\text { discussion }\end{array}$ & $\begin{array}{l}\text { Nepal [58] } \\
\text { Malaysia [59] }\end{array}$ \\
\hline ADR assessment & Medical & Bachelor/Master & ADR report analysis & Netherlands [60] \\
\hline ADR problem solving & Medical & Bachelor & Problem solving & Netherlands [61] \\
\hline Safe prescribing & Medical and nurse & 4th year & Interprofessional learning & USA [15] \\
\hline $\begin{array}{l}\text { Pharmacology course: risk } \\
\text { perception of ADRs }\end{array}$ & Medical & Bachelor 3rd year & Clinical training & France [62] \\
\hline $\begin{array}{l}\text { PV in pharmacoepidemiology } \\
\text { course }\end{array}$ & Biology and pharmacology & Not provided & Problem-based learning & Canada [63] \\
\hline
\end{tabular}

$A D R$ adverse drug reaction, $P V$ pharmacovigilance

local structure of educational programmes. The actual reporting of an ADR needs a real clinical context, which is offered at the end of most educational programmes.

As demonstrated by Hartman et al. [12] and Schutte et al. [7], the time for education on PV appears to be limited. The amount of contact hours for explicit PV education in medical, pharmacy and nurse education was about $2-5 \mathrm{~h}$ in the entire curriculum [12]. The limited time and the applicability in clinical practice forces the PV core curriculum for university teaching to be confined to clinical aspects. The multidimensional character of PV education requires integration of key aspects in existing pharmacotherapy courses or methods such as prescribing safety assessments (PSA) [38]. In PSA, the evaluation of preventing, recognizing and managing ADRs should be incorporated as defined by the Guide to Good Prescribing [39].

\subsection{PV in Educational Frameworks}

Educational frameworks and medical codes of conduct provide a formal basis on which to integrate PV aspects into existing curricula [18]. For pharmacy and medical students, preventing and handling ADRs, as well as reporting ADRs to national PV centres, are listed in the frameworks [17, 40-43]. In Europe, a set of 252 learning outcomes for clinical pharmacology and therapeutics (CPT) education was published recently to harmonize medical education. The key PV aspects are covered in the description of the CPT learning outcomes [19].
Preventing, recognizing and managing ADRs and PV elements are lacking in educational frameworks for nurses everywhere, although patient safety in general is regarded as an important topic [44, 45]. Furthermore, it has been shown that nurses are thoroughly capable of recognizing and reporting ADRs [5, 46].

\section{Examples of Undergraduate PV Education}

The ways in which PV is taught differs according to country [12]. In some European countries, PV has been integrated at a high level in therapeutics courses or programmes such as PSA [18]. In developing countries, pharmacotherapy education has its own challenges, and PV is less well developed, both in general and in education [47]. A few examples of PV educational methods at universities are described in the literature and summarized in Table 2. Most of these examples show active learning elements, such as developing a reporting form, reporting an actual ADR, assessing causality of ADR reports, problembased learning and group discussions. Active and contextual educational methods have proven to be effective ways of transferring knowledge [48]. However, education is currently almost exclusively aimed at ADR reporting. Studies have demonstrated that educational interventions for HCPs about PV positively influenced ADR reporting in the short term [14, 49-52]. There are no long-term studies of the PV competencies of university students after graduation. 
In this WHO PV core curriculum for university teaching, we propose a shift from a regulatory focus, which has $\mathrm{ADR}$ reporting as a main learning outcome, to a more healthcare-focussed approach. Such a clinical approach integrates key PV aspects into existing pharmacology education programmes, with the aim of decreasing druginduced harm in patients. We believe that awareness of the impact of ADRs stimulates students' interest in PV. It could be expected that students are motivated to report in future if they regard ADRs and PV as important topics.

Active learning methods are preferred over passive learning methods such as lectures to obtain competences [36]. Authentic learning activities that prepare students for their professional tasks can motivate learning. Case studies, problem-based learning, simulations, the use of entrustable professional activities and internships at PV centres can be effective [36]. Methods can be adjusted according to each country's situation.

\section{Conclusion and Future Steps}

This paper provides an outline of the WHO PV core curriculum for university teaching, in which competencies and key aspects of PV for future HCPs have been formulated. In today's busy clinical practice, drug-related problems such as the prevention, recognition and management of ADRs do not always get the attention they need. When students are competent at preventing, recognizing and managing ADRs, they can and will improve the safe use of drugs.

Since PV is important for all HCPs in clinical and public health disciplines, key PV aspects should be integrated into existing programmes and courses for medical, pharmacy, dentistry and nursing education. We emphasise that the key PV aspects are intended to be add-in elements. Therefore, we expect that integrating PV elements into existing courses requires a limited time investment.

As a first step, universities would need to recognize possible gaps in their educational programmes and provide opportunities for teachers to integrate elements of the PV core curriculum for university teaching. National PV centres or other PV stakeholders can stimulate and facilitate PV education for students. For example, they can provide 'teach the teacher' courses to train university teachers about PV. Second, in countries where reporting ADRs is a challenge, PV education at a university level can take place in parallel with improving the reporting system.

Further discussions are needed to develop materials and share experiences to integrate key PV aspects in university teaching. A second stakeholder meeting was held in 2017 to discuss materials, teaching methods and strategy for sharing and implementation. Participants from the second meeting came from various parts of the world and are actively involved in PV education at universities, as PV staff or as university teachers. The main outcomes were to develop a web portal for sharing materials and to construct a 'teach the teacher' programme to promote PV education to university staff who are less familiar with PV.

To meet PV competencies in clinical practice, a cultural change is required in healthcare institutions in which PV is not yet common practice. The number of pharmaceutical products is increasing, as is the number of patients across the world with access to these treatments. The central role for PV, aiming at the safety and safe use of medicines, is fundamental for future HCPs. By developing PV competencies at universities, we may take the first step in this journey of change.

Acknowledgements The authors acknowledge Shanti Narayan Pal, Noha Iessa and Viola Macolic Sarinic of the WHO for their recommendations on the manuscript and the Advisory Committee on Safety of Medicinal Products (ACSoMP) for their recommendations on the curriculum.

\section{Compliance with ethical standards}

Conflicts of interest Rike van Eekeren, Leàn Rolfes, Andries Koster, Lara Magro, Gurumurthy Parthasarathi, Hussain al Ramimmy, Tim Schutte, Daisuke Tanaka, Eugène van Puijenbroek and Linda Härmark have no conflicts of interest that are directly relevant to the content of this study.

Funding The Netherlands Pharmacovigilance Centre Lareb as WHO Collaborating Centre for Pharmacovigilance in Education and Patient Reporting received funding from the WHO for the organization of the stakeholder meeting, held in September 2016, 's-Hertogenbosch, the Netherlands.

Open Access This article is distributed under the terms of the Creative Commons Attribution-NonCommercial 4.0 International License (http://creativecommons.org/licenses/by-nc/4.0/), which permits any noncommercial use, distribution, and reproduction in any medium, provided you give appropriate credit to the original author(s) and the source, provide a link to the Creative Commons license, and indicate if changes were made.

\section{References}

1. Pirmohamed M, James S, Meakin S, Green C, Scott AK, Walley T, Farrar K, Park BK, Breckenridge AM. Adverse drug reactions as cause of admission to hospital: prospective analysis of 18820 patients. BMJ. 2004;329(7456):15-9.

2. Leendertse AJ, Egberts ACG, Stoker LJ, van den Bemt PMLA. HARM Study group. Frequency of and risk factors for preventable medication related hospital admissions in The Netherlands. Arch Intern Med. 2008;168(17):1890-6.

3. Angamo MT, Chalmers L, Curtain CM, Bereznicki LRE. Adverse drug reaction related hospitalisations in developed and developing countries: a review of prevalence and contributing factors. Drug Saf. 2016;39(9):847-57.

4. Rolfes L, van Hunsel F, Taxis K, van Puijenbroek E. The impact of experiencing adverse drug reactions on the patient's quality of 
life; a retrospective cross-sectional study in The Netherlands. Drug Saf. 2016;39(8):769-76.

5. Kaeding M, Schmalter J, Klika C. Pharmacovigilance in the European Union. Practical implementation across member states. New York: Springer; 2017.

6. World health Organisation. The importance of pharmacovigilance-safety monitoring of medicinal products. 2002. http:// apps.who.int/medicinedocs/en/d/Js4893e/. Accessed $28 \mathrm{Mar}$ 2018.

7. Schutte T, Tichelaar J, Reumerman MO, van Eekeren R, Rissman R, Kramers C, Richir M, van Puijenbroek EP, van Agtmael MA. Pharmacovigilance skills, knowledge and attitudes in our future doctors-a nationwide study in the Netherlands. Basic Clin Pharmacol Toxicol. 2017;120(5):475-81.

8. Elkalmi RM, Hassali MA, Ibrahim MIM, Widodo RT, Efan QMA, Hadi MA. Pharmacy student's knowledge and perceptions about pharmacovigilance in Malaysian public universities. Am J Pharm Educ. 2011;75(5):96. https://doi.org/10.5688/ajpe75596.

9. Othman GQ, Ibrahim MIM, Alshakka M, Ansari M, Al-Qadasi F, Halboup AM. Knowledge and perception about pharmacovigilance among pharmacy students of universities in Sana's Yemen. J Clin Diagn Res. 2017;11(6):FC09-13.

10. Khan MU, Ahmad A, Ejaz A, Rivzi SA, Sardar A, Hussain K, Zaffar T, Jamshed SQ. Comparison of the knowledge, attitudes and perception of barriers regarding adverse drug reaction reporting between pharmacy and medical students in Pakistan. J Educ Eval Health Prof. 2015;12:28. https://doi.org/10.3352/ jeehp.2015.12.28.

11. Maxwell S. How should teaching of undergraduates in clinical pharmacology and therapeutics be delivered and assessed? $\mathrm{Br} \mathbf{J}$ Clin Pharmacol. 2012;73(6):893-9.

12. Hartman J, Harmark L, van Puijenbroek EP. A global view of undergraduate education in pharmacovigilance. Eur J Clin Pharmacol. 2017;7(73):891-9.

13. Waller P. An Introduction to pharmacovigilance. Chichester: Wiley-Blackwell; 2010. p. 34-8.

14. Pagotto C, Varallo F, Mastroianni P. Impact of educational interventions on adverse drug events reporting. Int $\mathrm{J}$ Technol Assess Health Care. 2013;29(4):410-7.

15. Achike FI, Smith J, Leonard S, Williams J, Browning F, Glisson J. Advancing safe drug use through interprofessional training (IPL): a pilot study. J Clin Pharmacol. 2014;54(7):832-9.

16. Arici MA, Gelal A, Demiral Y, Tuncok Y. Short and long-term impact of pharmacovigilance training on the pharmacovigilance knowledge of medical students. Indian J Pharmacol. 2015;47(4):436-9.

17. Rouse MJ. Quality assurance of pharmacy education: the FIP global framework. International Pharmaceutical Federation; 2014. http://fip.org/files/fip/PharmacyEducation/Quality_Assuranc e/QA_Framework_2nd_Edition_online_version.pdf. Accessed 28 Mar 2018.

18. General Medical Council. Good medical practice. UK, 2013 [Updated 2014 Apr 29]. https://www.gmc-k.org/Good_medical_ practice__English_1215.pdf_51527435.pdf. Accessed 28 Mar 2018.

19. Brinkman DJ, Tichelaar J, Mokkink LB, Christiaens T, Likic R, Maciulaitis R, Costa J, Sanz EJ, Maxwell SR, Richir MC, van Agtmael MA, for the Education Working Group of the European Association for Clinical Pharmacology and Therapeutics (EACPT) and its affiliated Network of Teachers in Pharmacotherapy (NOTIP). Key learning outcomes for clinical pharmacology and therapeutics education in Europe: a modified Delphi study. Clin Pharmacol Ther. 2017. https://doi.org/10. $1002 /$ cpt.962 (Epub ahead of print).

20. World Health Organisation. Patient Safety Curriculum guide, Multi-professional edition. 2011. http://www.who.int/patient safety/education/mp_curriculum_guide/en/. Accessed 28 Mar 2018.

21. Bate A, Beckmann J, Dodoo A, Harmark L, Hartigan-Go K, Hegerius A, Lindquist M, van Puijenbroek EP, Tuccori M, Hagemann U. Developing a crowdsourcing approach and tool for pharmacovigilance education material delivery. Drug Saf. 2017;40(3):191-9.

22. Beckmann J, Hagemann U, Bahri P, Bate A, Boyd IW, Dal Pan GJ, Edwards BD, Edwards IR, Hartigan-Go K, Lindquist M, McEwen J, Moride Y, Olssen S, Pal SN, Soulaymani-Bencheikh R, Tuccori M, Vaca CP, Wong ICK. Teaching pharmacovigilance: the WHO-ISoP core elements of a comprehensive modular curriculum. Drug Saf. 2014;37:743-59.

23. Eu2P. The first European training programme in pharmacovigilance and pharmacoepidemiology. 2009-2018. https://www.eu2p. org/about-eu2p/education-programme. Accessed 28 Mar 2018.

24. Berhe DF, Taxis K, Haaijer-Ruskamp FM, Mulugeta A, Mengistu YT, Burgerhof JGM, Mol PGM. Impact of adverse drug events and treatment satisfaction on patient adherence with antihypertensive medication - a study in ambulatory patients. Br J Clin Pharmacol. 2017;83(9):2107-17.

25. Ward S. Thalidomide and congenital abnormalities. BMJ. 1962;2(5305):646-7.

26. Lavan AH, Gallagher P. Predicting risk of adverse drug reactions in older adults. Ther Adv Drug Saf. 2016;7(1):11-22.

27. Gromek K, Drumond N, Simas P. Pharmacovigilance of herbal medicines. Int J Risk Saf Med. 2015;27(2):55-65.

28. Bailey DG, Malcolm J, Arnold O, Spence JD. Grapefruit juicedrug interactions. Br J Clin Pharmacol. 1998;46(2):101-10.

29. Meijboom RHB, Lindquist M, Egberts ACG. An ABC of drug related problems. Drug Saf. 2000;22(6):415-23.

30. Aronson JK, Ferner RE. Joining the DoTS: new approach to classifying adverse drug reactions. BMJ. 2003;327(7425):1222-5.

31. Baiardini I, Gaeta F, Molinengo G, Braido F, Canonica GW, Romano A. Quality-of-life issues in survivors to anaphylactic reactions to drugs. Allergy. 2015;70(7):877-9.

32. Edwards BD, Tilson HH, West SL. Defining the competencies of those conducting Pharmacovigilance. Pharmacoepidemiol Drug Saf. 2006;15(3):193-8.

33. Routledge PA, O'Mahony MS, Woodhouse KW. Adverse drug reactions in elderly patients. $\mathrm{Br} \mathrm{J}$ Clin Pharmacol. 2003;57(2):121-6.

34. Trifiro G, Patadia V, Schuemie MJ, Coloma PM, Gini R, Herings R, Hippisley-Cox J, Mazzaglia G, Giaquinto C, Scotti L, Pedersen L, Avillach P, Sturkenboom MC, van der Lei J. EU-ADR healthcare database network vs spontaneous reporting system database: preliminary comparison of signal detection. Stud Health Technol Inform. 2011;166:25-30.

35. Forehand M. Bloom's taxonomy. University of Georgia; 2017. http://epltt.coe.uga.edu/index.php?title=Bloom\%27s_Taxonomy. Accessed 28 Mar 2018.

36. Koster AS, Schalekamp T, Meijerman I. Implementation of competency based pharmacy education (CBPE). Pharmacy. 2017;1(5):1-16.

37. Mejicano GC, Bumsted TN. Describing the journey and lessons learned implementing a competency-based, time-variable undergraduate medical education curriculum. Acad Med. 2018;93(3):S42-8.

38. MSC Assessment and British Pharmacological Society. Prescribing Safety assessment. 2016 [cited 2018 mar 28]. https:// prescribingsafetyassessment.ac.uk/.

39. de Vries TPGM, Henning RH, Hogerzeil HV, Fresle DA. Guide to good prescribing - a practical manual. World Health Organization; 1994. http://apps.who.int/medicinedocs/en/d/Jwhozip23e/. Accessed 28 Mar 2018. 
40. World Health Organisation, Federation International Pharmaceutique. Good pharmacy practice. Joint FIP/WHO guidelines on GPP, standards of quality for pharmacy services; 2012. https:// www.fip.org/www/uploads/database_file.php?id=331\&table_id. Accessed 28 Mar 2018.

41. Royal Pharmaceutical Society. A competency framework for all prescribers. UK, 2016. https://www.rpharms.com/Portals/0/RPS\% 20document\%20library/Open\%20access/Professional\%20standards/ Prescribing\%20competency\%20framework/prescribingcompetency-framework.pdf. Accessed 28 Mar 2018.

42. Atkinson J, De Paepe K, Sanchez-Pozo A, Rekkas D, Volmer D, Hirvonen J, Bozic B, Skowron A, Mirciouiu C, Marcincal A, Koster AS, Wilson KA, Varallo F. The second round of the PHAR-QA survey of competences for pharmacy practice. Pharmacy. 2016;4 (3):27.

43. Ross S, Maxwell SR. Prescribing and the core curriculum for tomorrow's doctors: BPS curriculum in clinical pharmacology and prescribing for medical students. $\mathrm{Br} \mathrm{J}$ Clin Pharmacol. 2012;74:644-61.

44. The Nursing and Midwifery Council. Standards for competence for registered nurses; 2014. https://www.nmc.org.uk/standards/ additional-standards/standards-for-competence-for-registered-nurses/. Accessed 11 Jan 2018.

45. Canadian Association of schools of Nursing. National nursing education framework; 2015. https://www.casn.ca/competencyguidelines/national-nursing-education-framework/. Accessed 11 Jan 2018.

46. Schutte T, van Eekeren R, Richir M, van Staveren J, van Puijenbroek EP, Tichelaar J, van Agtmael MA. The adverse drug reaction reporting assignment for specialist oncology nurses: a preliminary evaluation of quality, relevance and educational value in a prospective cohort study. Naunyn Schmiedebergs Arch Pharmacol. 2018;391(1):17-26. https://doi.org/10.1007/s00210017-1430-z.

47. Abubakar AR, Chedi BA, Mohammed KG, Haque M. Perception of Nigerian medical students on adverse drug reaction reporting. J Adv Pharm Technol Res. 2015;6(4):154-8. https://doi.org/10. 4103/2231-4040.165021.

48. May F. Teaching and learning pharmacovigilance. In: Andrews EB, Moore N, editors. Mann's pharmacovigilance. 3rd ed. Hoboken: Wiley; 2014. p. 793-804.

49. Gerritsen R, Faddegon H, Dijkers F, van Grootheest K, van Puijenbroek EP. Effectiveness of pharmacovigilance training of general practitioners: a retrospective cohort study in the Netherlands comparing two methods. Drug Saf. 2011;34(9):755-62.

50. Jha N, Rathore DS, Shankar PR, Bhandary S, Pandit RB, Gyawali S, Alshakka M. Effect of an educational intervention on knowledge and attitude regarding pharmacovigilance and consumer pharmacovigilance among community pharmacists in Lalitpur district, Nepal. BMC Res Notes. 2017;10(1):4.

51. Yu YM, Lee E. Enhanced knowledge of spontaneous reporting with structured educational programs in Korean community pharmacists: a cross-sectional study. BMC Med Educ. 2017;17(1):95.

52. Sarayani A, Naderi-Behdani F, Hdavand N, Javadi M, Farsad F, Hadjibabaie M, Gholami K. A 3-armed randomized controlled trial of nurses' continuing education meetings on adverse drug reactions. J Contin Educ Health Prof. 2015;35(2):123-30.

53. Sears EL, Generali JA. Adverse drug reaction and medication error reporting by pharmacy students. Ann Pharmacother. 2005;39:452-9.

54. Sullivan KM, Spooner LM. Adverse drug reaction reporting by pharmacy students in a teaching hospital. Am J Health Syst Pharm. 2008;65:1177-9.

55. Christensen ST, Sondergaard B, Honore PH, Bjerrum OJ. Pharmacy student driven detection of adverse drug reactions in the community pharmacy setting. Pharmacoepidemiol Drug Saf. 2011;20(4):399-404.

56. Baniasadi S, Habibi M, Haghgoo R, Gamishan MK, Dabaghzadeh F, Farasatinasab M, Farsaei S, Gharekhami A, Kafi H, Karimzadeh A, Najmeddin F, Nikvarz N, Oghazian MB, Rezaee H, Sadeghi K, Tafazzaoli A, Shahsavari N, Fahimi F. Increasing the number of adverse drug reactions reporting: the role of clinical pharmacy residents. Iran J Pharm Res. 2014;13(1):291-7.

57. Tripathi RK, Jalgaonkar SV, Sarkate P, Rege NN. Implementation of a module to promote competency in adverse drug reaction reporting in undergraduate medical students. Indian J Pharmacol. 2016;48(Suppl 1):S69-73.

58. Subish P, Khanal S, Alam K, Paudel A. Introducing pharmacovigilance to postgraduate pharmacy students in Nepal. 6. Am J Pharm Educ. 2009;73:a114.

59. Al-lela OQB, Elkalmi RM, Jamshed SQ. New pharmacovigilance course at the international islamic university of Malaysia-IUMM. Am J Pharm Educ. 2013;77(5):a106.

60. Schutte T, Tichelaar J, Reumerman MO, van Eekeren R, Rolfes L, van Puijenbroek EP, Richir M, van Agtmael MA. Feasability and educational value of a student-run pharmacovigilance programme: a prospective cohort study. Drug Saf. 2017;40:409-18.

61. van Eekeren R, Schutte T. Netherlands national education programme. Uppsala Rep. 2015;70:18.

62. Durrieu G, Hurault C, Damase-Michel C, Montastruc JL. Perception of risk of adverse drug reactions: a 3-year follow up of a cohort of medical students. Fundam Clin Pharmacol. 2010;24(4):423-7.

63. Rangachari PK. Exploring the context of drug use: a problem based learning course in pharmacoepidemiology for undergraduate science students. Naunyn Schmiedeberg's Arch Pharmacol. 2004;369:184-91. 